\title{
CENÁRIO PARA AS CULTURAS DE MILHO E SOJA COM BASE NA SAFRA BRASILEIRA DE 2012/2013
}

MENDES, Edmar Eduardo Bassan ${ }^{1}$

ISSUE DOI: $10.3738 /$ nucleus.v0i0.904

\begin{abstract}
RESUMO: O empresário rural brasileiro, atualmente conta com uma variedade enorme de informações que necessitam ser bem avaliadas para se confiar e utiliza-las nas tomadas de decisões. O uso de dados oficiais como do Instituto de Economia Agrícola e da Companhia Nacional de Abastecimento, diminuem estes riscos. As culturas de milho e soja, juntas representam em área mais de $82 \%$ de tudo o que está plantado na safra 2012/13. Em termos de produção estimada, que pelo oitavo levantamento da CONAB será de mais de 184.000.000 de toneladas de grãos. A quantidade produzida junto pelas duas culturas é superior a 159.500 .000 toneladas, o que indica mais de $86 \%$ da produção a ser colhida nesta safra. Problemas climáticos em algumas regiões do Brasil e dos Estados Unidos da América têm prejudicado o desempenho de uma produção que pode garantir uma melhora nos "estoques de passagem" entre uma safra e outra. Isto sinaliza alterações para cima nos preços que estão sendo praticados a médio e longo prazo. Atualmente os produtores estão em plena colheita e isto por si provoca um aumento na oferta e consequente diminuição dos preços no curto prazo. As dificuldades de transporte e de armazenamento destes grãos, com uma demanda aquecida, principalmente pela China, tem mantido o mercado aquecido. O governo tem se mobilizado para manter os estoques em níveis aceitáveis. Em São Paulo, estado importador de milho tem mostrado que continuará a importar, pois o consumo vem superando em muito o total produzido em terras paulistas. A soja tem mostrado força na sua entrada em terras de reforma de canaviais, sendo bem maior a produção obtida neste ano, comparando-se com safras passadas no Estado de São Paulo, privilegiadas pela proximidades dos portos para exportação, e pela melhora nas variedades adaptadas as condições produtivas do solo e clima. As duas culturas tem sido importantes no resultado da Balança Comercial Brasileira.
\end{abstract}

Palavras-chave: Glycine max (L.) Merrill, Zea mays (L.), Produção de grãos.

\section{SCENARIO FOR CORN AND SOYBEAN BASED IN THE BRAZILIAN CROP YEAR 2012/2013}

\begin{abstract}
SUMMARY: The Brazilian rural businessman currently has a huge variety of information that need to be evaluated and to trust and use them in decision making. The use of official data such as the Instituto de Economia Agricola (IEA) and the Companhia Nacional de Abastecimento (CONAB), diminish risks. The corn and soybean area together represent for over $82 \%$ of everything that is planted in the 2012/13 crop. In terms of estimated production, that the eighth survey CONAB will be over 184 million tons of grain. The quantity produced by the two cultures together is more than 159.5 million tons, which indicates more than $86 \%$ of production to be harvested this season. Adverse weather in some regions of Brazil and the United States has impaired the performance of a production that can guarantee an improvement in "carryover stocks" between one season and another. This signals changes up the prices being charged in the medium and long term. Currently producers are in full harvest, and this in itself causes an increase in supply and consequent decrease in prices in the short term. The difficulties of transport and storage of these grains, with a strong demand, especially from China, has kept the hot market. The government has mobilized to maintain inventories at acceptable levels. In São Paulo, the state corn importer has shown that it will continue to import, as consumption is far outpacing the total produced in São Paulo lands. Soy has shown strength in its entry on land reform plantations, being much higher yield obtained this year, compared with past vintages in the State of São Paulo, privileged by nearby ports for export, and by improved varieties adapted productive soil conditions and climate. The two cultures have been important in the results of the Brazilian trade balance.
\end{abstract}

Keywords: Glycine $\max ($ L.) Merrill, Zea mays (L.), Grain production.

\footnotetext{
${ }^{1}$ Pesquisador Científico, MSc. - APTA - PRDTA Centro Norte - UPD de São José do Rio Preto, São José do Rio Preto, SP.
} 


\section{INTRODUÇÃO}

A grande quantidade de informações disponíveis ao produtor brasileiro, não garante a qualidade nem a confiabilidade, em razão dos interesses que promovem a divulgação de determinados dados.

Neste trabalho estaremos utilizando basicamente duas fontes oficiais: os dados da Companhia Nacional de Abastecimento (CONAB), em seu Acompanhamento da Safra Brasileira de Grãos - Safra 2012/2013 - Oitavo Levantamento em Maio de 2013 e os dados do Instituto de Economia Agrícola, (IEA), órgão do Governo do Estado de São Paulo que estuda as informações levantadas nas áreas paulistas, e são analisadas por pesquisadores com larga experiência no ramo. Baseados nestes dados oficiais, as inferências deste artigo refletem a visão de alguns analistas e a nossa percepção do que pode vir a ocorrer, em se mantendo o quadro climático e as reações do mercado, em resposta aos reflexos socioeconômicos do que vem ocorrendo atualmente no grande globo.

Inicialmente, apresentamos a tabela da área plantada na safra 2012/13 divulgada pela CONAB em sua oitava estimativa.

Disparadamente as culturas de milho e soja, são as mais representativas, correspondendo juntas a uma área de 43.401 .400 ha (15.686.200 ha de milho e 27.715.200 ha de soja). Da área total em produção 52.976.400 ha, apenas 18,08 \% ou seja, 9.575.000 ha estão sendo cultivadas por todas as outras culturas comerciais de grãos, ou seja, arroz, amendoim, feijão, girassol, mamona, sorgo, aveia, canola, centeio, cevada, trigo e triticale.

Somente por esta proporção, já é possível dimensionar a importância destas duas culturas em conjunto.

Os comentários sobre a cultura do milho que acompanham o levantamento da oitava safra da CONAB, divulgado em maio deste ano, observam que ao se comparar com o desempenho da safra anterior, nota-se que "houve a redução na área plantada da primeira safra, saindo de 7.558.000 ha no exercício passado, para 6.894.200 ha na atual temporada, representando em âmbito nacional, uma diferença de $8,8 \%$. Quem contribuiu de forma expressiva para esse resultado, foi o comportamento da safra nordestina, que pelo segundo ano consecutivo sofreu com a escassez das chuvas na região. No entanto, o maior responsável pela redução no plantio do milho de $1^{\mathrm{a}}$ safra foi a Região Centro-Sul, onde em praticamente todos os estados da região, os produtores optaram por incrementarem o plantio de soja nesse período utilizando-se das variedades precoces, para em seguida efetuar o plantio do milho de $2^{\mathrm{a}}$ safra, alterando uma tendência histórica de repartir o plantio nos dois períodos".

Este comportamento reflete o amadurecimento e o comprometimento empresarial que o agronegócio brasileiro vem experimentando. Produtores bem informados em um mundo conectado. 
Tabela 1. Brasil - Estimativa de área plantada - Safras 2011/2012 e 2012/2013.

BRASIL

ESTIMATIVA DA PRODUÇÃO DE GRÃOS

SAFRAS 2011/2012 E 2012/2013

(Em $1000 \mathrm{t})$

\begin{tabular}{|c|c|c|c|c|c|}
\hline \multirow{3}{*}{ PRODUTOS } & \multicolumn{3}{|c|}{ SAFRA } & \multicolumn{2}{|c|}{ VARIAÇÃO } \\
\hline & \multirow{2}{*}{$\begin{array}{c}2011 / 12 \\
\text { (a) }\end{array}$} & \multicolumn{2}{|c|}{$2012 / 13$} & \multirow{2}{*}{$\begin{array}{l}\text { Percentual } \\
\text { (c)/(a) }\end{array}$} & \multirow{2}{*}{$\begin{array}{c}\text { Absoluta } \\
\text { (c)-(a) }\end{array}$} \\
\hline & & $\begin{array}{c}\text { Abr/2013 } \\
\text { (b) }\end{array}$ & $\begin{array}{l}\text { Mai/2013 } \\
\text { (c) }\end{array}$ & & \\
\hline ALGODÃO - CAROÇO ${ }^{(1)}$ & $3.018,6$ & $2.000,9$ & $1.997,0$ & $(33,8)$ & $(1.021,6)$ \\
\hline ALGODÃO - PLUMA & $1.877,3$ & $1.263,4$ & $1.260,7$ & $(32,8)$ & $(616,6)$ \\
\hline AMENDOIM TOTAL & 294,7 & 312,8 & 326,2 & 10,7 & 31,5 \\
\hline AMENDOIM $1^{\text {a }}$ SAFRA & 274,6 & 286,2 & 300,0 & 9,2 & 25,4 \\
\hline AMENDOIM $2^{\text {a }}$ SAFRA & 20,1 & 26,6 & 26,2 & 30,3 & 6,1 \\
\hline ARROZ & $11.599,5$ & $11.943,4$ & $11.945,1$ & 3,0 & 345,6 \\
\hline FEIJÃO TOTAL & $2.918,5$ & $2.986,5$ & $2.856,3$ & $(2,1)$ & $(62,2)$ \\
\hline FEIJÃO $1^{\text {a }}$ SAFRA & $1.235,6$ & 986,3 & 984,9 & $(20,3)$ & $(250,7)$ \\
\hline FEIJÃO 2a SAFRA & $1.063,9$ & $1.258,3$ & $1.211,7$ & 13,9 & 147,8 \\
\hline FEIJÃO $3^{\text {a }}$ SAFRA & 619,0 & 741,9 & 659,7 & 6,6 & 40,7 \\
\hline GIRASSOL & 116,4 & 100,2 & 99,9 & $(14,2)$ & $(16,5)$ \\
\hline MAMONA & 24,9 & 63,1 & 24,7 & $(0,8)$ & $(0,2)$ \\
\hline MILHO TOTAL & $72.979,8$ & $77.451,9$ & $77.998,2$ & 6,9 & $5.018,4$ \\
\hline MILHO $1^{\text {a }}$ SAFRA & $33.867,1$ & $34.766,7$ & $34.810,5$ & 2,8 & 943,4 \\
\hline MILHO $2^{\mathrm{a}}$ SAFRA & $39.112,7$ & $42.682,2$ & $43.187,7$ & 10,4 & $4.075,0$ \\
\hline SOJA & $66.383,0$ & $81.940,6$ & $81.513,4$ & 22,8 & $15.130,4$ \\
\hline SORGO & $2.221,9$ & $2.116,6$ & $2.259,9$ & 1,7 & 38,0 \\
\hline SUBTOTAL & $159.557,3$ & $178.916,0$ & $179.020,7$ & 12,2 & $19.463,4$ \\
\hline AVEIA & 353,5 & 360,7 & 360,7 & 2,0 & 7,2 \\
\hline CANOLA & 52,0 & 60,5 & 60,5 & 16,3 & 8,5 \\
\hline CENTEIO & 3,5 & 3,7 & 3,7 & 5,7 & 0,2 \\
\hline CEVADA & 305,1 & 287,2 & 287,2 & $(5,9)$ & $(17,9)$ \\
\hline TRIGO & $5.788,6$ & $4.300,4$ & $4.300,4$ & $(25,7)$ & $(1.488,2)$ \\
\hline TRITICALE & 112,2 & 116,9 & 116,9 & 4,2 & 4,7 \\
\hline SUBTOTAL & $6.614,9$ & $5.129,4$ & $5.129,4$ & $(22,5)$ & $(1.485,5)$ \\
\hline BRASIL $^{(2)}$ & $166.172,2$ & $184.045,4$ & $184.150,1$ & 10,8 & $17.977,9$ \\
\hline
\end{tabular}

FONTE: CONAB - Levantamento: Maio/2013.

(1) Produção de caroço de algodão.

${ }^{(2)}$ Exclui a produção de algodão em pluma.

Em relação à estimativa da safra 2012/13, o Brasil produzirá $184.150 .100 \mathrm{t}$ de grãos, das quais $42,35 \%$ com milho $(77.998 .200$ t) e $44,27 \%$ com soja $(81.513 .400$ t). Juntas representam 86,62\% (159.511.600 t) do total a ser produzido na presente safra. Novamente, a desproporção destas duas culturas em relação às demais fica evidenciada, pois apenas $13,38 \%$ do total serão produzidos pelas demais culturas produtoras de grãos (arroz, amendoim, feijão, girassol, mamona, sorgo, aveia, canola, centeio, cevada, trigo e triticale). 
Tabela 2. Brasil - Estimativa da produção de grãos - Safras 2011/2012 e 2012/2013.

BRASIL

ESTIMATIVA DE ÁREA PLANTADA

SAFRAS 2011/2012 E 2012/2013

\begin{tabular}{|c|c|c|c|c|c|}
\hline \multirow{3}{*}{ PRODUTOS } & \multicolumn{3}{|c|}{ SAFRA } & \multicolumn{2}{|c|}{ VARIAÇÃO } \\
\hline & \multirow{2}{*}{$\begin{array}{c}2011 / 12 \\
\text { (a) }\end{array}$} & \multicolumn{2}{|c|}{$2012 / 13$} & \multirow{2}{*}{$\begin{array}{l}\text { Percentual } \\
\text { (c)/(a) }\end{array}$} & \multirow{2}{*}{$\begin{array}{l}\text { Absoluta } \\
\text { (c)-(a) }\end{array}$} \\
\hline & & $\begin{array}{c}\text { Abr/2013 } \\
\text { (b) }\end{array}$ & $\begin{array}{l}\text { Mai/2013 } \\
\text { (c) }\end{array}$ & & \\
\hline ALGODÃO & $1.393,4$ & 886,8 & 886,7 & $(36,4)$ & $(506,7)$ \\
\hline AMENDOIM TOTAL & 93,9 & 100,8 & 100,6 & 7,1 & 6,7 \\
\hline AMENDOIM $1^{\text {a }}$ SAFRA & 82,1 & 85,8 & 86,3 & 5,1 & 4,2 \\
\hline AMENDOIM $2^{\mathrm{a}}$ SAFRA & 11,8 & 15,0 & 14,3 & 21,2 & 2,5 \\
\hline ARROZ & $2.426,7$ & $2.409,5$ & $2.389,7$ & $(1,5)$ & $(37,0)$ \\
\hline FEIJÃO TOTAL & $3.262,1$ & $3.064,7$ & $2.952,7$ & $(9,5)$ & $(309,4)$ \\
\hline FEIJÃO $1^{\text {a }}$ SAFRA & $1.241,4$ & $1.121,1$ & $1.122,6$ & $(9,6)$ & $(118,8)$ \\
\hline FEIJÃO $2^{a}$ SAFRA & $1.394,6$ & $1.308,6$ & $1.275,4$ & $(8,5)$ & $(119,2)$ \\
\hline FEIJÃO $3^{\text {a }}$ SAFRA & 626,1 & 635,0 & 554,7 & $(11,4)$ & $(71,4)$ \\
\hline GIRASSOL & 74,5 & 70,0 & 60,4 & $(18,9)$ & $(14,1)$ \\
\hline MAMONA & 128,2 & 104,7 & 87,5 & $(31,7)$ & $(40,7)$ \\
\hline MILHO TOTAL & $15.178,1$ & $15.627,3$ & $15.686,2$ & 3,3 & 508,1 \\
\hline MILHO $1^{\text {a }}$ SAFRA & $7.558,5$ & $6.985,2$ & $6.879,2$ & $(9,0)$ & $(673,3)$ \\
\hline MILHO $2^{a}$ SAFRA & $7.619,6$ & $8.642,1$ & $8.807,0$ & 15,6 & $1.187,4$ \\
\hline SOJA & $25.042,2$ & $27.713,3$ & $27.715,2$ & 10,7 & $2.673,0$ \\
\hline SORGO & 786,9 & 797,3 & 836,4 & 6,3 & 49,5 \\
\hline SUBTOTAL & $48.386,0$ & $50.774,4$ & $50.715,4$ & 4,8 & $2.329,5$ \\
\hline AVEIA & 153,0 & 168,7 & 168,7 & 10,3 & 15,7 \\
\hline CANOLA & 42,4 & 43,8 & 43,8 & 3,3 & 1,4 \\
\hline CENTEIO & 2,3 & 2,3 & 2,3 & - & - \\
\hline CEVADA & 88,4 & 102,8 & 102,8 & 16,3 & 14,4 \\
\hline TRIGO & $2.166,2$ & $1.895,4$ & $1.895,4$ & $(12,5)$ & $(270,8)$ \\
\hline TRITICALE & 46,9 & 48,0 & 48,0 & 2,3 & 1,1 \\
\hline SUBTOTAL & $2.499,2$ & $2.261,0$ & $2.261,0$ & $(9,5)$ & $(238,2)$ \\
\hline BRASIL & $50.885,2$ & $53.035,4$ & $52,976,4$ & 4,1 & $2.091,3$ \\
\hline
\end{tabular}

FONTE: CONAB - Levantamento: Maio/2013.

É evidente que as nossas características edafoclimáticas, os hábitos culturais e as tradições interferem na decisão da escolha por estas duas atividades, no entanto a força do peso econômico que elas movimentam, e o seu poder de gerar renda é que fazem os empresários rurais a optarem por elas.

Distribuídas de norte a sul, neste país de dimensão continental, suas características adaptativos fazem com que em algumas regiões, tornem quase que exclusivas como alternativas, ou se rotacionem entre si.

Algumas culturas enfrentam a dificuldade da adaptação climática, no entanto o milho e a soja passaram por um processo de melhoramento genético ao longo destes últimos trinta anos, que possibilitaram a adaptação nas mais diversas regiões, climas e solos, além de um avanço em índices de produtividade. Hoje temos produtividade na cultura da soja, similares a índices obtidos nas maiores regiões produtoras dos EUA. Este avanço se deve a ousadia dos empresários desbravando novas fronteiras, até então tidas como desconhecidas, para desenharem um novo "lay out" do agronegócio nacional brasileiro. Alia-se a isto as instituições de pesquisa que lançaram novos cultivares e desenvolveram pacotes tecnológicos que possibilitaram tais avanços. 
O consumo interno brasileiro faz com que estas duas atividades produtoras não diminuam a intensidade da necessidade de novas fronteiras e índices de serem ultrapassados. A economia aquecida faz que crianças devorem mais iogurtes e famílias saiam aos finais de semana para consumirem pizza, aumentando o consumo de derivados de lácteos e outros produtos que tem na agricultura o inicio de sua cadeia produtiva. Compreende desde o algodão para fazer as roupas para o passeio, o alimento a ser consumido, a pipoca no cinema e até o leitinho da hora de dormir... isto é muito bom e alimenta a economia.

O governo federal vem se estruturando para a compra e reposição dos estoques de milho que atualmente se encontram em níveis baixos. Segundo o secretário de Política Agrícola do Ministério da Agricultura, Neri Geller, inicialmente o governo irá comprar um milhão de toneladas por meio de contratos de compra a termo, aprovados pelo Conselho Interministerial de Estoques Públicos de Alimentos (CIEP). A intenção é "balizar os preços do mercado e assegurar a renda dos produtores rurais". A intenção é garantir um nível de estoque final de passagem na ordem de 17.000 t., de acordo com os comentários que acompanham a divulgação do levantamento da CONAB.

A oitava previsão realizada pela $\mathrm{CONAB}$, não contabilizou os prejuízos que a estiagem de abril e maio 2013 provocou nas lavouras da safrinha, e outras em fase de desenvolvimentos. Estes reflexos serão contabilizados nos levantamentos futuros. O que fica evidente é que a quebra é inevitável.

Se houver a confirmação de mais uma safra recorde de milho no Brasil, próxima a 78.000.000 t., onde 55,36\% do total estão na segunda safra, os preços devem cair. Com o início da colheita o mercado interno já mostra sinais de enfraquecimento, principalmente, nas regiões produtoras onde o transporte e as dificuldades de armazenamento atingem mais diretamente os grãos prontos.

Eventos climáticos extremos, como os tornados na Carolina do Norte, EUA em áreas de produção de milho e soja, aliados a estiagem que tem atrasado o plantio da safra de verão americana, também poderão trazer um desequilíbrio na oferta de produto ao final da safra americana, trazendo influencia nos preços desta comoditie.

Em relação à soja, a área plantada no Brasil, com 27.732.000 ha, na temporada 2012/13, apresenta um incremento de $10,7 \%$ em comparação com o verificado na temporada 2011/12, e representa um novo recorde. Esta também é uma informação contida na apresentação do oitavo levantamento, que completa afirmando que a produtividade média registrada para a Região Centro-Sul apresentou um incremento de $14,7 \%$, quando comparado com o observado no exercício anterior. Vale destacar a repercussão do desempenho do clima na produtividade em dois dos principais estados produtores da oleaginosa, no Paraná e no Rio Grande do Sul, que apresentaram neste levantamento, incrementos de 36\% e 69,8\%, respectivamente. O destaque negativo fica por conta do que foi registrado na Região Norte-Nordeste, duramente afetadas pela estiagem.

Resumindo, os efeitos dessas ocorrências no cômputo geral da safra brasileira apontou para este exercício uma produção estimada de 81.513.400 t. que ao se comparar com os 66.383 .000 t. em 2012, representa um aumento de mais de $22 \%$, segundo a CONAB.

A maior safra de grãos, noticiada pelo USDA, nos EUA, pode não ser confirmada, em razão dos recentes efeitos decorrentes de um comportamento anormal no clima, sobretudo nas maiores regiões produtoras. Isto faz com que o cenário e as variações de preço se alterem a cada boletim meteorológico, lá nos Estados Unidos e também aqui no Brasil.

Os preços internos e internacionais da soja estão acima da média histórica. Estes valores estão em alta devido a alguns eventos: 1- Receio do mercado internacional com a logística de exportação brasileira; 2 - Os baixos estoques mundiais; 3 - O baixo índice de plantio norte americano; 4 - A aquecida demanda chinesa pelo grão. Há uma expectativa de que o Brasil exporte aproximadamente 36.780 .000 ton. em 2013 
e que o estoque de passagem da safra 2012/13 fique em torno de 2.873 .300 toneladas.

A Tabela 3 resume os principais dados das últimas quatro safras produzidas no Brasil, e uma estimativa da atual. O Balanço de Oferta e Demanda, ao ser analisado, evidencia um real avanço do agronegócio brasileiro.

Neste Balanço podem ser observados os baixos estoques de passagem de uma safra para outra, e inferir um risco iminente se as demandas forem aumentadas em função de uma melhor renda por parte dos brasileiros ou pela necessidade de importação por parte de algum país, como EUA e China, que atualmente são os termômetros de preço e os maiores consumidores do mundo.

As exportações brasileiras aumentaram de ano a ano em todos os produtos, demonstrando a capacidade de produzir respondendo aos incentivos, ou simplesmente reagindo às adversidades, criando alternativas e melhorando processos para se fazer um campo forte, responsável por recordes sucessivos na Economia Nacional.

Tabela 3. Balanço de oferta e demanda.

BALANÇO DE OFERTA E DEMANDA

\begin{tabular}{|c|c|c|c|c|c|c|c|c|}
\hline PRODUTO & SAFRA & $\begin{array}{l}\text { ESTOQUE } \\
\text { INICIAL }\end{array}$ & PRODUÇÃO & IMPORTAÇÃO & SUPRIMENTO & CONSUMO & EXPORTAÇÃO & $\begin{array}{l}\text { ESTOQUE } \\
\text { FINAL }\end{array}$ \\
\hline \multirow{5}{*}{$\begin{array}{l}\text { ALGODÃO } \\
\text { EM PLUMA }\end{array}$} & $2008 / 09$ & $\begin{array}{r}675.0 \\
\end{array}$ & $1.213,7$ & 14.5 & 1.903.2 & $1.004,1$ & 504.9 & 394,2 \\
\hline & $2009 / 10$ & 394.2 & $1.194,1$ & 39.2 & $1.627,5$ & $1.039,0$ & 512.5 & 76.0 \\
\hline & $2010 / 11$ & 76.0 & $1.959,8$ & 144.2 & $2.180,0$ & 900,0 & 758.3 & 521.7 \\
\hline & $2011 / 12$ & 521.7 & $1.877,3$ & 3.5 & $2.402,5$ & 865,0 & $1.052,8$ & 484.7 \\
\hline & $2012 / 13$ & 484.7 & $1.260,7$ & 180.0 & $1.925,4$ & 887,0 & 612.0 & 426.4 \\
\hline \multirow{5}{*}{$\begin{array}{c}\text { ARROZ EM } \\
\text { CASCA }\end{array}$} & $2008 / 09$ & $2.033,7$ & $12.602,5$ & 908.0 & $15.544,2$ & $12.118,3$ & 894.4 & $2.531,5$ \\
\hline & $2009 / 10$ & $2.531,5$ & $11.660,9$ & $1.044,8$ & $15.237,2$ & $12.152,5$ & 627.4 & $2.457,3$ \\
\hline & $2010 / 11$ & $2.457,3$ & $13.613,1$ & 825.4 & $16.895,8$ & $12.236,7$ & $2.089,6$ & $2.569,5$ \\
\hline & $2011 / 12$ & $2.569,5$ & $11.599,5$ & $1.068,0$ & $15.237,0$ & $12.100,0$ & $1.455,2$ & $1.681,8$ \\
\hline & 2012/13 & $1.681,8$ & $11.945,1$ & 900.0 & $14,526,9$ & $12.100,0$ & 1.100 .0 & $1.326,9$ \\
\hline \multirow{5}{*}{ FEIJÃO } & $2008 / 09$ & 230.0 & $3.502,7$ & 110.0 & $3.842,7$ & $3.500,0$ & 25.0 & 317.7 \\
\hline & $2009 / 10$ & 317.7 & $3.322,5$ & 181.2 & $3.821,4$ & $3.450,0$ & 4.5 & 366.9 \\
\hline & $2010 / 11$ & 366.9 & $3.732,8$ & 207.1 & $4.306,8$ & $3.600,0$ & $20 . .4$ & 686.4 \\
\hline & $2011 / 12$ & 686.4 & $2.918,4$ & 312.3 & $3.917,1$ & $3.500,0$ & 43.3 & $\overline{373.8}$ \\
\hline & $2012 / 13$ & 373.8 & $2.856,7$ & 400.0 & $3.630,5$ & $3.400,0$ & 50.0 & 180.5 \\
\hline \multirow{5}{*}{ MILHO } & $2008 / 09$ & $7.675,5$ & $51.003,8$ & $1.181,6$ & $59.860,9$ & $45.414,1$ & $7.333,9$ & $7.112,9$ \\
\hline & $2009 / 10$ & $7.112,9$ & $56.018,1$ & 391.9 & $63.522,9$ & $46.967,6$ & $10.966,1$ & $5.589,2$ \\
\hline & $2010 / 11$ & $5.589,2$ & $57.406,9$ & 764.4 & $63.760,5$ & $48.485,5$ & $9.311,9$ & $5.963,1$ \\
\hline & $2011 / 12$ & $5.963,1$ & $72.979,5$ & 774.0 & $79.716,6$ & $51.533,4$ & $22.313,7$ & $5.869,5$ \\
\hline & $2011 / 12$ & $5.869,5$ & $77.998,2$ & 300.0 & $84.167,7$ & $52.053,9$ & $15.000,0$ & $17.113,8$ \\
\hline \multirow{5}{*}{$\begin{array}{l}\text { SOJA EM } \\
\text { GRÄOS }\end{array}$} & $2008 / 09$ & $4.540,1$ & $57.161,6$ & 99.4 & $61.801,1$ & $32.564,0$ & $28.562,7$ & 674.4 \\
\hline & $2009 / 10$ & 674,4 & $68.688,2$ & 117.8 & $69.480,4$ & $37.800,0$ & $29.073,2$ & $2.607,2$ \\
\hline & $2010 / 11$ & $2.607,2$ & $75.324,3$ & 41.0 & $77.972,5$ & $41.970,0$ & $32.986,0$ & $3.016,5$ \\
\hline & $2011 / 12$ & $3.016,5$ & $66.383,0$ & 266.5 & $69.666,0$ & $36.754,0$ & $32.468,0$ & 444.0 \\
\hline & $2012 / 13$ & 444.0 & $81.513,4$ & 100.0 & $82.057,4$ & $42.401,4$ & $36.782,7$ & $2.873,3$ \\
\hline \multirow{5}{*}{$\begin{array}{l}\text { FARELO } \\
\text { DE SOJA }\end{array}$} & $2008 / 09$ & $3.053,0$ & $23.187,8$ & 43.5 & $26.284,3$ & $12.000,0$ & $12.253,0$ & $2.031,3$ \\
\hline & $2009 / 10$ & 2.031 .3 & $26.719,0$ & 39.5 & $28.789,8$ & $12.300,0$ & $13.668,6$ & $2.821,2$ \\
\hline & $2010 / 11$ & $2.821,2$ & $29.298,5$ & 24.8 & $32.144,5$ & $13.400,0$ & $14.355,0$ & $4.389,5$ \\
\hline & $2011 / 12$ & $4.389,5$ & $26.026,0$ & 15.0 & $30.430,5$ & $13.950,0$ & $14.289,0$ & $2.191,5$ \\
\hline & $2012 / 13$ & $2.191,5$ & 29.739 .5 & 36.0 & $31.967,0$ & $14.325,0$ & $14.925,0$ & $2.717,0$ \\
\hline \multirow{5}{*}{$\begin{array}{l}\text { ÓLEO DE } \\
\text { SOJA }\end{array}$} & $2008 / 09$ & 246,2 & $5.872,2$ & 27.4 & $6.145,8$ & $4.250,0$ & $1.593,6$ & 302.2 \\
\hline & $2009 / 10$ & 302,2 & $6.766,5$ & 16.2 & $7.084,9$ & $4.980,0$ & $1.563,8$ & $\overline{541.1}$ \\
\hline & $2010 / 11$ & 541,1 & $7.419,8$ & 0.1 & $7.961,0$ & $5.400,0$ & $1.741,0$ & 820.0 \\
\hline & $2011 / 12$ & 820,0 & $6.591,0$ & 0.0 & $7.411,0$ & $5.495,0$ & $1.757,1$ & 158.9 \\
\hline & $2012 / 13$ & 158,9 & $7.531,4$ & 1.0 & $7.691,3$ & $5.640,0$ & $1.750,0$ & 301.3 \\
\hline \multirow{6}{*}{ TRIGO } & $2008 / 09$ & 895,7 & $5.884,0$ & $5.676,4$ & $12.456,1$ & $9.398,0$ & 351,4 & $2.706,7$ \\
\hline & $2008 / 10$ & $2.706,7$ & $5.026,2$ & $5.922,2$ & $13.655,1$ & $9.614,2$ & $1.170,4$ & $2.870,5$ \\
\hline & $2009 / 11$ & $2.870,5$ & 5.881 .6 & $5.771,9$ & $14.524,0$ & $10.242,0$ & $2.515,9$ & $1.766,1$ \\
\hline & $2010 / 12$ & $1.766,1$ & $5.788,6$ & $6.011,8$ & $13.566,5$ & $10.444,9$ & $1.901,0$ & $1.220,6$ \\
\hline & $2012 / 13$ & $1.220,6$ & $4.300,4$ & $7.200,0$ & $12.721,0$ & $10.552,3$ & $1.541,8$ & 626,9 \\
\hline & $2013 / 14$ & 626,9 & $5.144,0$ & $6.800,0$ & $12.570,9$ & $10.701,1$ & $1.200,0$ & 669,8 \\
\hline
\end{tabular}

Recentemente o governo brasileiro deu os primeiros passos com o objetivo de melhorar os níveis dos estoques de passagem, preparando ações para compra de safra que está em curso e sinaliza com um plano de safra 2013/14 com alterações que podem incentivar o agronegócio brasileiro, como queda de juros, aumentos de limites de contratação e outros mecanismos que viabilizem as atividades produtoras primárias, que ao longo de anos e anos tem garantido o equilíbrio de nossa balança comercial. 


\section{Panorama no Estado de São Paulo}

\section{Milho}

Em se tratando de demanda, apresentamos um levantamento oficial da oferta e demanda de milho no Estado de São Paulo (Tabela 4). Logo na primeira linha da tabela, confirma-se o nível de estoque baixo, estando abaixo do início da safra passada.

São Paulo continuará a importar milho, pois seu consumo estimado de 9.504 .100 t., requisita uma importação 4.258 .300 t. de outras regiões, considerando que sua produção total estimada para a safra 2012/13 será de 4.628.600 t., segundo os dados do IEA.

Em um mercado onde se importa milho de outras regiões e a proximidade dos portos exportadores de grãos faz com que os pesquisadores TSUNECHIRO; MIURA (2013) do IEA, creiam que o Estado de São Paulo "prossiga participando do significativo desempenho das exportações brasileiras de milho em 2013, tal como em 2012, dadas as condições favoráveis do mercado internacional e da vantagem comparativa do produtor paulista em relação aos produtores do Centro-Oeste quanto ao frete rodoviário, com a proximidade ao porto de Santos".

Tabela 4. Oferta e Demanda de Milho, Estado de São Paulo, 2011/2013 (ton.).

\begin{tabular}{|c|c|c|c|c|c|}
\hline Especificação & $\begin{array}{r}2011 \\
\text { (0) }\end{array}$ & $\begin{array}{r}2012 \\
\text { (b) }\end{array}$ & $\begin{array}{r}\text { Var. \% } \\
\text { (b/o) }\end{array}$ & $\begin{array}{r}2013 \\
\text { (C) }\end{array}$ & $\begin{array}{r}\text { Var. } \% \\
\text { (c/b) }\end{array}$ \\
\hline Estoque inicial & 613,200 & 641.700 & 4,6 & 617,200 & $-3,8$ \\
\hline Produção & $4.071,000$ & $4.755,100$ & 16,8 & $4.628,600$ & $-2,7$ \\
\hline Primeira safra (verão) & $3.281,000$ & $3.400,900$ & 3,7 & $3.250,600$ & $-4,4$ \\
\hline Segunda safra (safrinha) & 790.000 & $1.354,200$ & 71,4 & $1.378,000$ & 1,8 \\
\hline Disponibilidade interna & $4.684,200$ & $5.396,800$ & 15,2 & $5.245,800$ & $-2,8$ \\
\hline Importação & $4.488,100$ & $4.089,400$ & $-8,9$ & $4.258,300$ & 4,1 \\
\hline Oferta total & $9.172,300$ & $9.486,200$ & 3,4 & $9.504,100$ & 0,2 \\
\hline Consumo & $8.463,300$ & $8.210,100$ & $-3,0$ & $8.311,700$ & 1,2 \\
\hline Animal & $6.547,100$ & $6.299,900$ & $-3,8$ & $6.431,600$ & 2,1 \\
\hline Avicultura de corte & $2.999,800$ & $2.759,800$ & $-8,0$ & $2.759,800$ & 0,0 \\
\hline Avicultura de postura & $1.121,700$ & $1.121,700$ & 0,0 & $1.177,800$ & 5,0 \\
\hline Suinocultura & 918.200 & 895.200 & $-2,5$ & 908.600 & 1,5 \\
\hline Pecuária leiteira & 388.000 & 395.800 & 2,0 & 403.700 & 2,0 \\
\hline Pecuária de corte & 206,500 & 196.200 & $-5,0$ & 202.100 & 3,0 \\
\hline Outros animais & 912.900 & 931.200 & 2,0 & 979.600 & 5,2 \\
\hline Industrial & $1.260,000$ & $1.230,000$ & $-2,4$ & $1.230,000$ & 0,0 \\
\hline Não comercial & 656.200 & 680.200 & 3,7 & 650.100 & $-4,4$ \\
\hline Exportação & 10.800 & 594.700 & 5406,5 & 500.000 & $-15,9$ \\
\hline Sementes e perdas & 56.500 & 64.200 & 13,6 & 62.700 & $-2,3$ \\
\hline Demanda total & $8.530,600$ & 8.869 .000 & 4,0 & $8.874,400$ & 0,1 \\
\hline Estoque final & 641.700 & 617.200 & $-3,8$ & 629.700 & 2,0 \\
\hline
\end{tabular}

${ }^{1}$ Primeira estimativa para 2013, aprovada em reunião de 26/03/2013.

${ }^{2}$ Ano-safra 2012-13 - 01/01/2013 a 31/12/2013.

${ }^{3}$ Estimado em $20 \%$ da produção da primeira safra.

${ }^{4}$ Estimado em 30 dias de consumo comercial.

Fonte: Câmara Setorial de Milho, da Secretaria de Agricultura e Abastecimento do Estado de São Paulo. 
Soja

O Estado de São Paulo vem se firmando como um bom produtor de soja, e sua produção. Angelo et al. (2013), confirmam as previsões de intenção de plantio no Estado e observam que a soja paulista apresenta uma boa recuperação na área, com expansão de 8,3\% e melhor resultado na produção, com $17,9 \%$ de crescimento, o que resulta em um aumento na produtividade de $8,9 \%$, em relação à safra agrícola 2011/12.

Este mesmo grupo de pesquisadores ressalta um fator a ser considerado: a participação da China como grande comprador da soja brasileira favorecendo a manutenção da demanda e das cotações do produto no mercado internacional. Outro fator positivo é, novamente, as proximidades dos portos, que facilitam a exportação em São Paulo, e a diminuição do cultivo da soja nos Estados Unidos, que favorecem a implantação da soja nas regiões paulistas.

Em São Paulo a soja vem ganhando espaço e as áreas de reforma de canaviais, são importantes fronteiras que estão sendo alcançadas.

\section{REFERÊNCIAS}

AGRICULTURA RURAL. Governo usará contrato a termo para compra de milho: estoques oficiais do cereal estão em níveis historicamente baixos. Disponível em:

$<$ http://agricultura.ruralbr.com.br/noticia/2013/05/governo-usara-contrato-a-termo-para-compra-de-milho4132332.html> . Acesso em: 20 maio 2013.

ANGELO, J. A. et al. Previsões e Estimativas das Safras Agrícolas do Estado de São Paulo, Ano Agrícola 2012/13, $2^{\circ}$ Levantamento e Levantamento Final, Ano Agrícola 2011/12, nov. 2012. Disponível em: 〈http://www.iea.sp.gov.br/out/verTexto.php?codTexto=12563 〉. Acesso em: 20 maio 2013.

CONAB - COMPANHIA NACIONAL DE ABASTECIMENTO. Acompanhamento de safra brasileira: grãos, oitavo levantamento, maio 2013 / Companhia Nacional de Abastecimento. Brasília: Conab,2013. Publicação mensal.1. Safra. 2. Grão. Disponível em:

$\langle$ http://www.conab.gov.br/OlalaCMS/uploads/arquivos/13_05_09_11_56_07_boletim_2_maio_2013.pdf〉 . Acesso em: 16 maio 2013.

TSUNECHIRO, A.; MIURA, M. Primeira estimativa de oferta e demanda de milho no Estado de São Paulo em 2013. Disponível em:

<http://www.iea.sp.gov.br/out/verTexto.php?codTexto=12610>. Acesso em: 16 maio 2013. 